\title{
Metal-Oxide Arrester Fault Diagnosis based on Flexible Detection System
}

\author{
Miao $\mathrm{Yu}^{1, \mathrm{a}}$, Mengzhou Zhu ${ }^{1, \mathrm{~b}}$, Guang Chen ${ }^{1, \mathrm{c}}$, Jianhua Zhou ${ }^{1, \mathrm{~d}}$ and Song \\ $\mathrm{GaO}^{1, \mathrm{e}}$
}

1State Grid Jiangsu Electric Power Research Institute, Paweier Road 1, Jiangning District, Nanjing 211103, China

ayumiaosdu@foxmail.com, bmengzhou99@163.com, ctanzhongtan@163.com, dzhoujianhua83@126.com, ehvgaosong@qq.com

Keywords: MOA; flexible detection; arresters; full current; high voltage

Abstract. Metal-Oxide Arrester(MOA) is to limit the lightning overvoltage and operating overvoltage, and protect other electrical equipment from overvoltage damage. The fault diagnosis of MOA is very important to power system, traditional test methods has several factors to restrict the efficiency and accuracy. Based on the flexible detection, which is designed as a cyber-physical architecture for industry 4.0-based power equipment detection system, a new MOA electrified tester is developed. It can not only obtain the voltage signal in a safe and convenient way but also can technically eliminate the interference of the electric field around. The device can be used for all arrester electrified test occasions. It can greatly reduce the risk of measurement as well as significantly improve the measurement accuracy.

\section{Introduction}

Arrester is one kind of electrical equipment to limit lightning overvoltage which transmits by the line or internal overvoltage which to cause by the operation, and paralleled in nearby of equipment which be protects, make them to avoid harm by overvoltage, arrester has not protective function if it exists fault, and in serious it can influence other equipment running and spawn accident. Therefore, it is an important target of safety and economical running of power system whether does the arrester reliably move.

Since conventional methods of power equipment detection suffer from low test efficiency, time-consuming transportation, high security risks and long reporting cycle, it hardly meets the need of highly reliable and efficient detection of power equipment in smart grids. To solve the problem, a cyber-physical architecture for industry 4.0-based power equipment detection system is proposed in this manuscript.

Therefore, a new MOA electrified tester is developed in this paper. It takes the voltage signal in a safe and convenient way, and restricts the interference of the electric field around. It makes well use of the flexible detection, improves the test efficiency greatly, reduce the risk of measurement.

\section{Flexible Detection and Metal-Oxide Arresters}

Flexible detection system for power equipment. The flexible detection technology is introduced into the detection of power supplies and a cyber-physical architecture for industry 4.0-based power equipment detection system is established in a $900 \mathrm{~m}^{2}$ building hall. Large screen display system and flexible detection hall is shown in Fig.1. The system can achieve test intelligent, sample transitions automation, data management information, solving the problems of traditional testing and significantly improving the detection efficiency of electrical equipment.

The proposed system of flexible power equipment testing technology and testing platform has completed detection of 17 batches with 19 kinds of electrical devices for Jiangsu power grid. In the near future, it will further improve the safety and reliability of Jiangsu power grid [1-3]. 

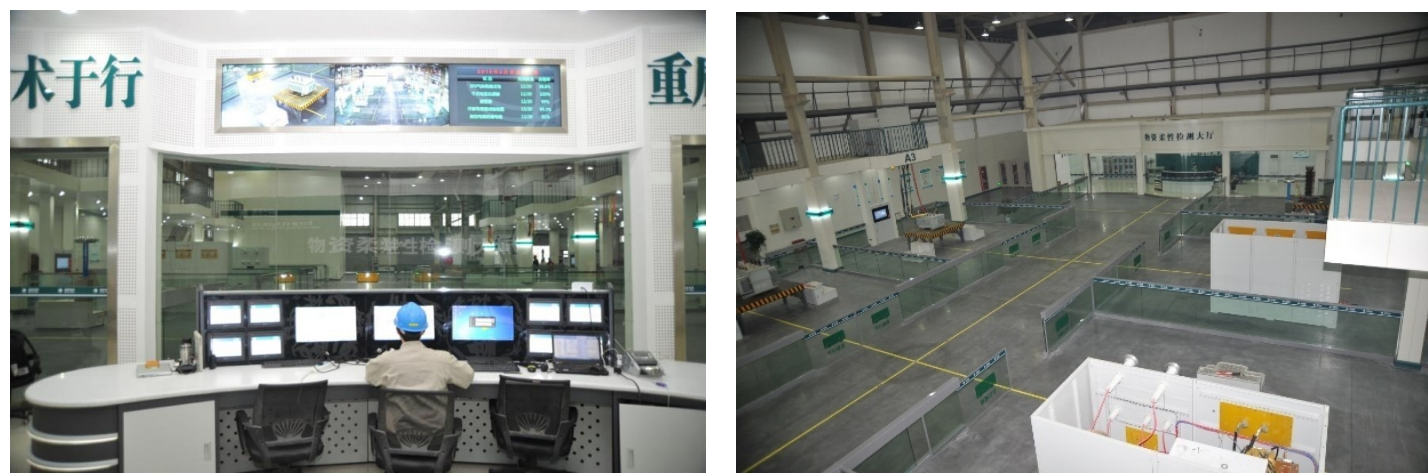

Fig. 1. Large screen display system and flexible detection hall in State Grid Jiangsu Electric Power Research Institute

Tasks and Operating Principles of Metal-Oxide Arresters. Surge arresters, or short arresters, constitute an indispensable aid to insulation coordination in electrical power supply systems. Fig. 2 makes this clear. There the voltages which may appear in a high-voltage electrical power system are given in per unit of the peak value of the highest continuous phase-to-earth voltage, depending on the duration of their appearance $[4,5]$.

The distinctive feature of an MO resistor is its extremely non-linear voltage-current or U-I characteristic, rendering unnecessary the disconnection of the resistors from the line through serial spark-gaps.

As a major progress, MO arresters could be built with only one single effective active element, namely the column of the MO resistors. High demands are, however, made on these MO resistors, as they combine all the functions, which previously had been shared among the different components of the gapped arrester. In this way they have to be ageing resistant while being subjected to constantly applied operating voltage. They must be able to absorb the energy injected during a discharge, and they should subsequently limit the follow current (leakage current) to values small enough for thermally stable operation $[6,7]$.

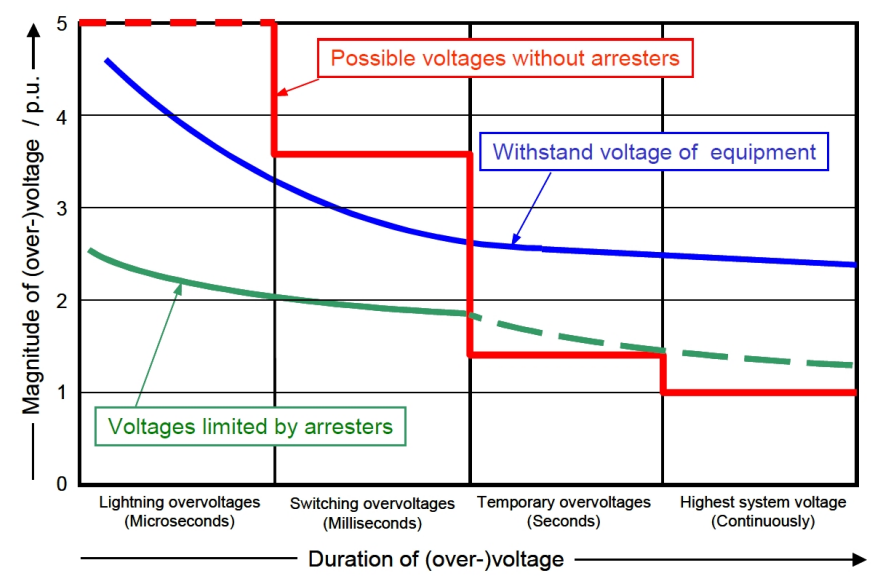

Fig. 2. Schematic representation of the magnitude of voltages and overvoltages in a high-voltage electrical power system versus duration of their appearance $\left(1\right.$ p.u. $\left.=\sqrt{2} U_{s} / \sqrt{3}\right)$

\section{Experiment on Zinc oxide arrester}

Wiring mode of MOA.A $\pm 5 \mathrm{kV}$ variable power supply is designed to compensate voltage automatically, as shown in Fig.3. The current going through Zinc oxide arrester MOA-1 can be obtained by subtracting the current value of ampere meter A- 2 from ampere meter A-1. Regulate the $\pm 5 \mathrm{kV}$ variable power supply until the current value of MOA-1 equals to $1 \mathrm{~mA}$, and the voltage value of DC-Voltage multiplier is recorded. Once the current value of MOA-2 reaches $1 \mathrm{~mA}$, another voltage data is recorded as well. The test system adjusts compensated voltage accordingly to estimate 
the unbalance of MOA-1 and MOA-2. On the other hand, it is feasible to test two $\mathrm{ZnO}$ arresters simultaneously on the condition of setting A-1 at $2 \mathrm{~mA}$ and A-2 at $1 \mathrm{~mA}$ precisely.

HV

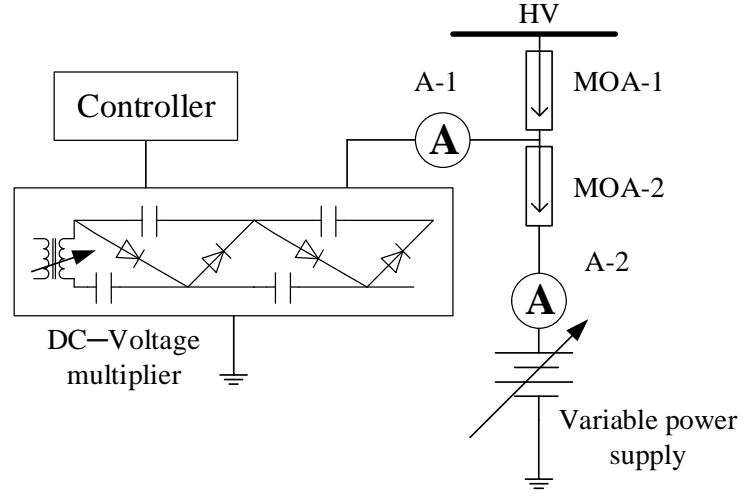

Fig. 3. Experimental setup of MOA

Experimental procedures. The overall procedures of $\mathrm{ZnO}$ arrester test is shown in Fig. 4, mainly includes experimental wiring, information input, leakage current detection, data acquisition, result analysis and so on. In the end, test reports of individual arresters are generated to give suggestion on the performance of the tested arresters.

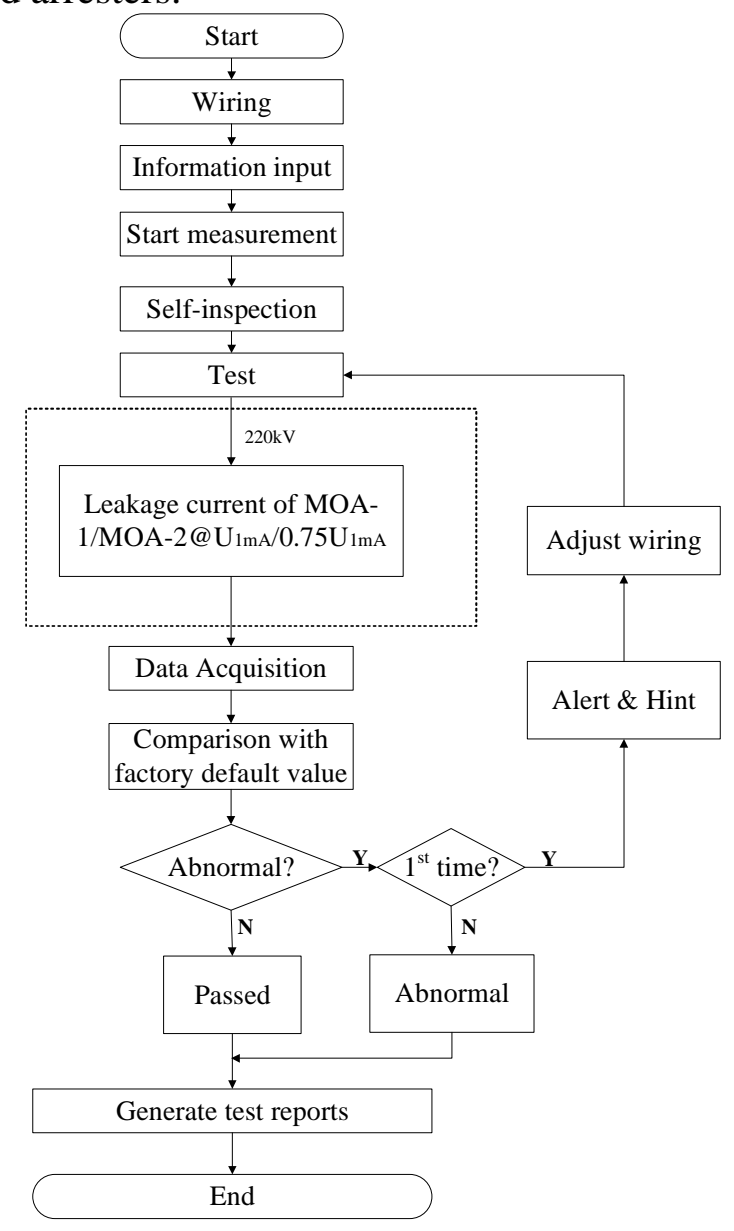

Fig. 4. Flowchart of MOA measurement in flexible detection system

Experimental detection of $\mathbf{Z n O}$ arresters. Commissioned by the Taizhou (a city in Jiangsu province) power company, State Grid Jiangsu Electric Power Research Institute carried out detection of 5 metal oxide surge arresters used in AC ring main unit (RMU). This kind of arresters are made up of composite coating and gapless mental oxide. Flexible test system was adopted to detect these arresters include items of DC resistance, DC voltage reference and leakage current at 0.75 times the 
DC reference voltage. Experimental results give technical support for the selection of arresters in RMU.

These MOA samples were labeled as BL-001, BL-002, BL-003, BL-004, BL-005. Three of them are $10 \mathrm{kV}$ lightning arresters, and the other two are $20 \mathrm{kV}$ lightning arresters, listed in Table 1. In addition, the product appearance was illustrated in Fig. 5.

TABLE I. SPECIFICATIONS OF THE ARRESTER SAMPLES TO BE DETECTED

\begin{tabular}{|c|c|c|c|}
\hline Sample & Detection NO. & RMU voltage & Rated voltage of MOA \\
\hline A & BL-001 & $10 \mathrm{kV}$ & $15 \mathrm{kV}$ \\
\hline B & BL-002 & $10 \mathrm{kV}$ & $15 \mathrm{kV}$ \\
\hline C & BL-003 & $10 \mathrm{kV}$ & $15 \mathrm{kV}$ \\
\hline D & BL-004 & $20 \mathrm{kV}$ & $34 \mathrm{kV}$ \\
\hline E & BL-005 & $20 \mathrm{kV}$ & $34 \mathrm{kV}$ \\
\hline
\end{tabular}

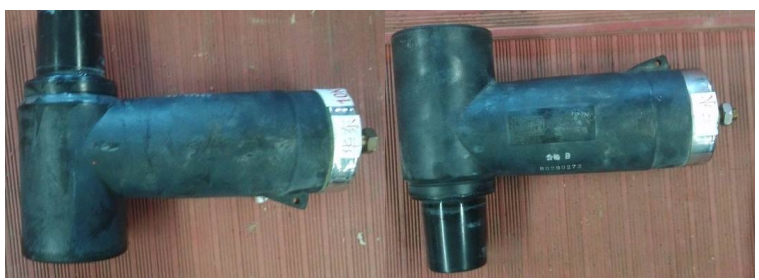

a) Sample $A$

b) Sample B

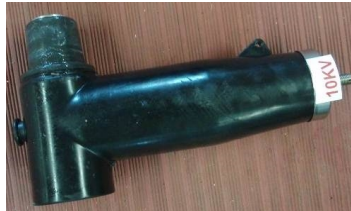

c) Sample C

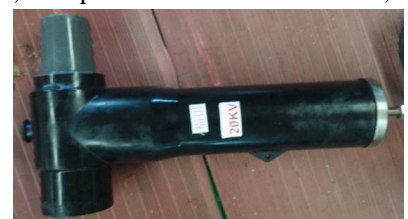

d) Sample D

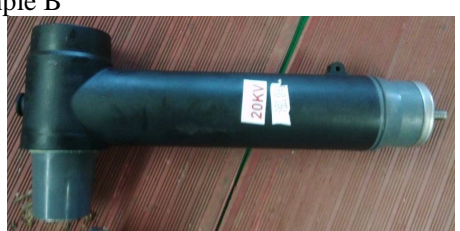

e) Sample E

Fig. 5. Appearance of 5 arrester samples

According to standard GB 11032-2010 Metal-oxide surge arresters without gaps for AC systems (IEC 60099-4: 2006, MOD), the insulation resistance of MOAs under $35 \mathrm{kV}$ should be less than 10 $\mathrm{G} \Omega$. Thus, the batch of arresters meets the requirement.

TABLE II. DC INSULATION RESISTANCE RESULTS

\begin{tabular}{|l|l|l|l|l|}
\hline $\mathbf{A}(\mathbf{G} \boldsymbol{\Omega})$ & $\mathbf{B}(\mathbf{G} \boldsymbol{\Omega})$ & $\mathbf{C}(\mathbf{G} \boldsymbol{\Omega})$ & $\mathbf{D}(\mathbf{G} \boldsymbol{\Omega})$ & $\mathbf{E}(\mathbf{G} \boldsymbol{\Omega})$ \\
\hline 6.060 & 5.857 & 5.662 & 5.466 & 5.269 \\
\hline
\end{tabular}

In fact, $1 \mathrm{~mA}$ reference voltage and the leakage current under the 0.75 times reference voltage reflect the inflection position of the characteristic curve. The two important parameters determine the lightning arrester characteristics, which directly reflect the lightning arrester is whether aging and damping or not. Experimental results under DC voltage reference are recorded in Table xx. Sample A, B, C qualified the standards GB 11032-2010 and Q/GDW-10-J206-2010.

DC reference voltage and leakage current at 0.75 times reference voltage of sample D fail to meet the standards. Regarding sample E, the DC reference voltage value was slightly lower than the requirements, but the leakage current was normal.

TABLE III. DETECTION RESUlts AT DC REFERENCE VOLTAGE

\begin{tabular}{|c|c|c|c|c|}
\hline \multicolumn{5}{|c|}{ DC reference voltage $U_{1 \mathrm{~mA}} \mathrm{DC}(\mathrm{kV})$} \\
\hline A & $\mathrm{B}$ & $\mathrm{C}$ & $\mathrm{D}$ & E \\
\hline 27.2 & 27.5 & 26.7 & $一^{\mathrm{a}}$ & 47.3 \\
\hline \multicolumn{5}{|c|}{ Leakage current at 0.75 times DC reference voltage $\mathrm{I}_{0.75 \mathrm{U} 1 \mathrm{~mA} \text { DC }}(\mu \mathrm{A})$} \\
\hline A & $\mathrm{B}$ & $\mathrm{C}$ & $\mathrm{D}$ & $\mathrm{E}$ \\
\hline 4 & 4 & 6 & - $^{\mathrm{a}}$ & 4 \\
\hline
\end{tabular}

a. Sample D made corona noises stressed $30 \mathrm{kV}$ and the leakage current reached $340 \mu \mathrm{A}$ stressed $48 \mathrm{kV}$. Due to exceeded leakage current, the stressed voltage did not increase to avoid any risks. 
Full current and resistive current was measured stressed by continual operating voltage. $13.6 \mathrm{kV}$ was stressed on MOA rating $17 \mathrm{kV}$ and $27.2 \mathrm{kV}$ was stressed on arrester rating $34 \mathrm{kV}$.

TABLE IV. FULL/RESISTIVE CURRENT MEASUREMENT UNDER CONTINUOUS HIGH VOLTAGE

\begin{tabular}{|c|c|c|c|c|}
\hline Sample & Voltage (kV) & $\begin{array}{c}\text { Full current } \\
\mathbf{I}_{\mathbf{x}}(\mathbf{m A})\end{array}$ & $\begin{array}{c}\text { Resistive } \\
\text { current } \mathbf{I}_{\mathbf{r}}(\mathbf{m A})\end{array}$ & $\mathbf{I}_{\mathbf{r}} / \mathbf{I}_{\mathbf{x}}$ \\
\hline \multirow{2}{*}{$\mathrm{A}$} & 13.7 & 0.479 & 0.068 & $14 \%$ \\
\cline { 2 - 5 } & 17.1 & 0.634 & 0.238 & $37 \%$ \\
\hline \multirow{2}{*}{ B } & 13.7 & 0.465 & 0.068 & $15 \%$ \\
\cline { 2 - 5 } & 17.2 & 0.598 & 0.187 & $31 \%$ \\
\hline \multirow{2}{*}{ C } & 13.7 & 0.345 & 0.070 & $20 \%$ \\
\cline { 2 - 5 } & 17.1 & 0.469 & 0.139 & $29 \%$ \\
\hline \multirow{2}{*}{ D } & $\mathbf{-}^{\mathrm{a}}$ & - $^{\mathrm{a}}$ & - $^{\mathrm{a}}$ & - $^{\mathrm{a}}$ \\
\hline \multirow{2}{*}{$\mathrm{E}$} & 27.2 & 3.953 & 1.102 & $28 \%$ \\
\cline { 2 - 5 } & 34.1 & 6.808 & 3.492 & $51 \%$ \\
\hline
\end{tabular}

According to the above information, it can be preliminarily determined that sample A, B, C are normal, sample D is out of operation, and there is defect in sample E. Since the ratio value of resistive component and full current stressed less than $25 \%$ meets the standard, it was nothing wrong with sample A, B and C. Nevertheless, sample D and E were subjected to further detection.

In March 2015, State Grid Jiangsu Electric Power Research Institute cut off parts of sample D inner insulation, and the disassembled photo was shown in Fig.6. Then the outer sleeve and valve stem were peeled off from sample E, which could be seen from Fig. 6.
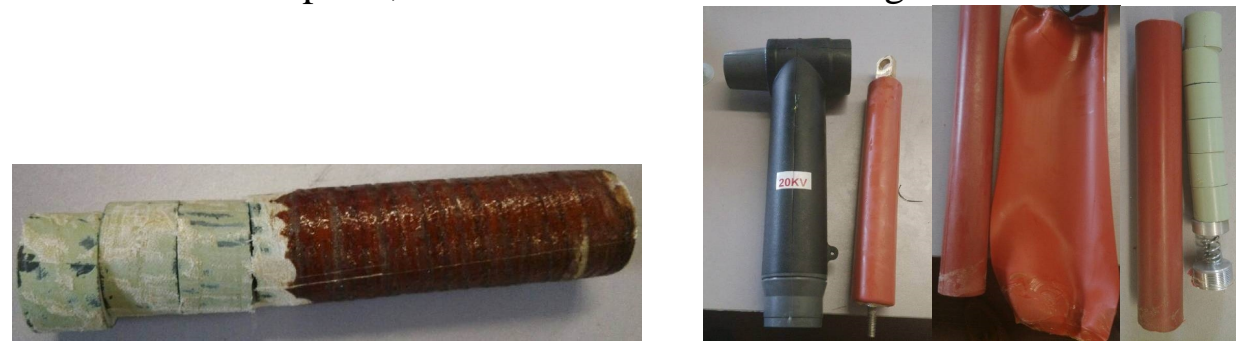

Fig. 6. Disintegration photos of sample D and E

After the disintegration, it was investigated that the defect of sample D was caused by insulation failure between the insulating jacket and interlayer rubber, while the defect of sample $\mathrm{E}$ was mainly due to the stains on $\mathrm{ZnO}$ valves. The results gave immediate evidence to the flexible detection system.

State Grid Jiangsu Electric Power Research Institute made full use of flexible detection technology in arrester sampling inspection to ensure power equipment quality before access to power grids. It is of great importance to avoid enormous risks due to arresters and blackout of power grid, laying the foundation for stable operation of the transmission system.

\section{Conclusion}

This article preliminary analysis some characteristic of heat of each kind of arrester under the normal and fault state, has some rule of infrared image in normal and fault state through simulate test and practice of locale detection.

Application of factory flexible detection system can effectively detect equipment abnormalities, improve the reliability level of power grid and provide technical support for improving the health status of power apparatuses.

\section{Acknowledgement}

This work was financially supported by technology project of State Grid Corporation of China, $\mathrm{n}$ amed "Research and Application of Haze Meteorological Early Warning and Evaluation Technology for Power Grid ". 


\section{References}

[1] Lee, Jay, B. Bagheri, and H. A. Kao. "A Cyber-Physical Systems architecture for Industry 4.0-based manufacturing system." Manufacturing Letters 3(2015):18-23

[2] OvidiuVermesan, and PeterFriess. Internet of things - from research and innovation to market deployment. River Publishers, 2014

[3] Miao Yu, Mengzhou Zhu, Guang Chen, et al. "A cyber-physical architecture for industry 4.0-based power equipments detection system." International Conference on Condition Monitoring and Diagnosis IEEE, 2016:782-785

[4] Khodsuz, Masume, and M. Mirzaie. "Monitoring and identification of metal-oxide surge arrester conditions using multi-layer support vector machine." Iet Generation Transmission \& Distribution 9.16(2015):2501-2508

[5] Almeida, Carlos A. Laurentys. "Intelligent detection and diagnosis of lightning arrester faults using digital thermovision image processing techniques." Proceedings of SPIE - The International Society for Optical Engineering 5782(2005):109-120

[6] Shejiao Han, Dong Dai, Xikui Ma, et al. " Calculation of potential distribution for zinc-oxide surge arrester by finite eiement method." Proceedings Of The Chinese Society For Electrical Engineering 21.12(2001):105-108

[7] Lira, George R. S., E. G. Costa, and C. W. D. Almeida. "Self-organizing maps applied to monitoring and diagnosis of $\mathrm{ZnO}$ surge arresters." Transmission and Distribution Conference and Exposition: Latin America IEEE, 2011:659-664 